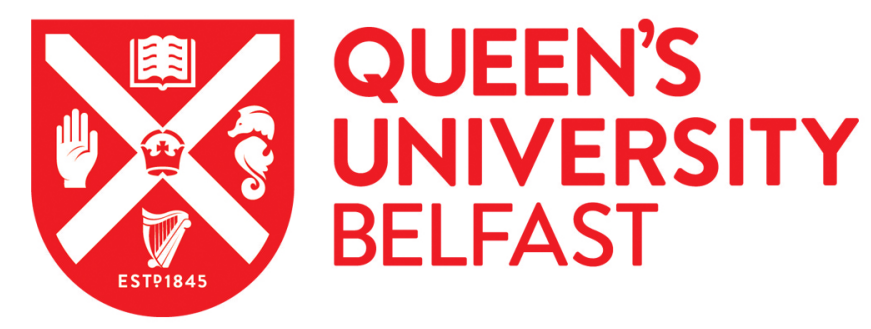

\title{
Quantifying intraherd cattle movement metrics: Implications for disease transmission risk
}

Campbell, E. L., Bryne, A. W., Menzies, F. D., Milne, G., McBride, K. R., McCormick, C. M., Scantlebury, D. M., \& Reid, N. (2020). Quantifying intraherd cattle movement metrics: Implications for disease transmission risk. Preventive veterinary medicine, 185, [105203]. https://doi.org/10.1016/j.prevetmed.2020.105203

Published in:

Preventive veterinary medicine

Document Version:

Peer reviewed version

Queen's University Belfast - Research Portal:

Link to publication record in Queen's University Belfast Research Portal

Publisher rights

(C) 2020 Elsevier Ltd.

This manuscript is distributed under a Creative Commons Attribution-NonCommercial-NoDerivs License

(https://creativecommons.org/licenses/by-nc-nd/4.0/), which permits distribution and reproduction for non-commercial purposes, provided the author and source are cited.

\section{General rights}

Copyright for the publications made accessible via the Queen's University Belfast Research Portal is retained by the author(s) and / or other copyright owners and it is a condition of accessing these publications that users recognise and abide by the legal requirements associated with these rights.

Take down policy

The Research Portal is Queen's institutional repository that provides access to Queen's research output. Every effort has been made to ensure that content in the Research Portal does not infringe any person's rights, or applicable UK laws. If you discover content in the Research Portal that you believe breaches copyright or violates any law, please contact openaccess@qub.ac.uk. 
1 Quantifying intraherd cattle movement metrics: implications for disease

2 transmission risk

3 Emma L. Campbell ${ }^{1,2^{*}}$, Andrew W. Byrne ${ }^{1,3}$, Fraser D. Menzies $^{4}$, Georgina Milne', 4 Kathryn R. McBride ${ }^{4}$, Carl M. McCormick ${ }^{4}$, D. Michael Scantlebury ${ }^{2}$, Neil Reid ${ }^{2}$ 5

6 *Corresponding author: Emma Campbell, Address - AFBI, DSIB VSD, 12 Stoney Road, Belfast, 7 Co. Antrim, BT4 3SD. Email - emma.campbell@afbini.gov.uk. Telephone - 02890525749.

8

9

10

11

12

13

14

15

\section{Author Affiliations:}

1. Agri-Food and Biosciences Institute, Veterinary Sciences Division, Belfast, UK.

2. School of Biological Sciences, Institute for Global Food Security (IGFS), Queen's University Belfast, Belfast, UK.

3. Department of Agriculture, Fisheries Food and Marine, Agriculture House, Kildare St, Dublin, Ireland.

4. Veterinary Epidemiology Unit, Department of Agriculture, Environment and Rural Affairs (DAERA), Belfast, UK

Word count: 3,309 (excluding title page, abstract, references, figures and tables)

Declarations of interest: none. 
There is a paucity of data quantifying on-farm management practices such as the frequency of intraherd cattle movements, use of consolidated or spatially fragmented grazing pastures, and duration of time cattle spend at grass with respect to biosecurity and disease transmission. Such movement dynamics are important when attempting to understand the maintenance of chronic infectious disease, such as bovine tuberculosis (bTB). We captured empirical data on daily cattle movements for a sample of eighteen farms throughout one complete grazing season ( $n=18,988$ grazing days) and assessed these attributes in relation to herd bTB risk.

Dairy herds were stocked at significantly higher densities compared to beef production systems (6.6 animals/ha, 95\% confidence intervals (CI) $6.5-6.7$ and 4.1 animals/ha, 95\%CI $4.1-4.1$ respectively, $p<0.001)$. Most notably milking cows, were grazed at higher densities than other life stages (e.g. calves, heifers and bullocks) $(p<0.001)$ and experienced four times the number of movements between pastures. Beef cattle were more likely to be grazed across multiple (rather than single) fields $(p<0.001)$, with greater time spent on fragmented land away from the main/home farm $(p<0.001)$. None of the farm or herd attributes analysed (e.g. stocking density, frequency of movement, movement distances or land fragmentation) were associated with herd bovine tuberculosis (bTB) breakdowns during this study. However, there was a weak positive association between bTB breakdowns during the 3 years prior to the study and cattle movement distances $(p=0.05)$ and time spent on fragmented land $(p=0.08)$. After a bTB breakdown occurs, restrictions on animals moving out of these herds are implemented to control disease spread, yet we argue that more attention is needed on the role of intraherd grazing patterns in modelling disease transmission risk between herds.

Keywords: Cattle movements; Bovine tuberculosis; Disease Control; Mycobacterium bovis; 
Bovine tuberculosis (bTB) is a disease of cattle, primarily caused by infection with

Mycobacterium bovis. The disease mainly affects the respiratory system and transmission between cattle is thought to occur predominately through direct aerosol contact, but indirect contacts may play a role (Griffin et al., 1993; Phillips et al., 2003). Clinical disease is rarely encountered in countries where national disease eradication programmes identify infected animals through ante-mortem testing and removal early on in the course of infection (Collins, 2006).

Interherd contact of cattle between farms is a known risk factor in the spread of bTB and other infectious diseases (Broughan et al., 2016; Gates et al., 2014), and can facilitate the maintenance of disease despite control (Allen et al., 2018). Previous research of cattle movement networks suggests high connectedness between herds through animal movements and trade can occur (Brown et al., 2019). Direct contact between cattle from different herds can occur at agricultural shows, markets, veterinary practices, shared transport, shared housing and contact 'across-the-hedge' (so called 'none-to-nose' contact) between neighbouring herds (Dommergues et al., 2012; Robinson and Christley, 2007). Indeed, at an animal-level movement can be associated with metrics of infection (Byrne et al., 2017; Ramírez-Villaescusa et al., 2009).

There is an increased risk of a bTB herd breakdown if local herd prevalence is high (Doyle et al., 2014; White et al., 2013). Current knowledge of intraherd movements (between cattle within the same herd) during the grazing season is scarce, and the implications for the transmission of M. bovis is poorly understood (Allen et al., 2018; Brennan et al., 2008; Griffin et al., 1993). Cattle are commonly moved during the grazing season between fields to ensure 
movements between pastures during the grazing season could not only increase intraherd contact rates between different batches of cattle but also interherd contacts rates as cattle may be more frequently adjacent to neighbouring herds. Therefore, grazing movements may play a role in local networks of $M$. bovis transmission. In addition, wildlife can play a part in bTB breakdown risk (notably the European badger, in Britain and Ireland; Allen et al., 2018), and wildlife exposure risk varies spatially depending habitats and resources available across land parcels (Byrne et al., 2015; Campbell et al., 2019). Intraherd movement of animals may modulate this exposure risk, and may also impact on epidemiological studies investigating spatial associations between wild and domesticated hosts (Byrne et al., 2015; Vial et al., 2011).

The issue of intraherd movements is likely to vary spatially, explained in large part by local and regional land delineation practices, types of field boundary, patterns of land inheritance, ownership or lease, and frequency of cattle movements (depending on field size etc.). For example, patterns of local land inheritance in Ireland mean many farms have been divided between children, and therefore become fragmented i.e. fields within any one farm may not be spatially contiguous but there may be multiple scattered single fields or contiguous patches (Aalen, 1963). Moreover, some herd owners with small areas of land may purchase or rent additional land (called 'conacre') to make farms economically viable (Allen et al., 2018). Such land fragmentation may lead to longer distance and more frequent movements of cattle between consecutively grazed land parcels again potentially increasing intra - and inter- herd contacts, creating opportunities for bTB transmission.

High stocking densities may increase disease transmission (Neill et al., 1989). The highest risk of bTB spread within a herd is thought to occur when the animals are housed indoors (O'Reilly and Daborn, 1995). There are recommendations for stocking densities for housed cattle (Herzog et al., 2018) and whilst there are agri-environment scheme recommendations for stocking densities when at grass (e.g. habitat management and energy requirements), there are 
97 few recommendations for stocking densities of cattle in the wider countryside in relation to disease spread.

Brennan et al. (2008) described the difficulties in examining intra- and inter- herd contact rates as there is huge spatial and temporal variability, illustrating a high degree of structural complexity and heterogeneity. Due to the complexity of farming practices and the difficulty in getting on-farm information, there are currently no data available quantifying variation in stocking densities, duration of days spent on contiguous versus fragmented land and intraherd movement rates for a sample of working farms. Furthermore, there is a dearth of basic data in this space, to create rulesets to make better use of large-scale land parcel information systems, where they are available (for example, in Ireland and the UK; (Durr and Froggatt, 2002)).

This study aimed to capture empirical data on cattle movements for a sample of farms daily throughout one complete grazing season. The objectives were to quantify: 1) stocking densities of cattle at grass, 2) the amount of time spent on fragmented land and 3) intraherd movement parameters including number of moves, distance moved, and the total extent of grassland used for grazing. Furthermore, comparisons were made between these metrics and the major enterprise types (dairy versus non-dairy herds), and the disease (bTB) histories within these herds. These data will help describe real-world grazing practices and help parameterise future models of disease transmission risk with respect to intraherd movement.

\section{Material and Methods}

\section{Study site}

A total of 25 cattle farms ( $44 \%$ dairy and $56 \%$ beef) were surveyed in County Down, Northern Ireland, UK. The area had a high cattle density and was within a so-called 'bTB hotspot' with records of herd outbreak for many years (DAERA, 2018; Milne et al., 2019a; Wright et al., 
2015). The landscape was predominately improved grassland (pasture) grazed by cattle or used for silage production with some sheep grazing and a small proportion of interspersed arable fields.

\section{Quantifying time spent at grass}

Farmers were given an individual record book with maps of their own farms with each field given a Unique ID. Farmers recorded for every batch of cattle put out to graze the Unique ID of the field (i.e. its spatial location), the date during which cattle were turned out and subsequently moved on, the number of cattle and the batch life stage i.e. calves, heifers, bullocks or cows. Data were recorded daily from May to November 2016. Farmers were (re)engaged weekly by telephone to ensure recording was continuous and consistent. Monthly farm visits (by E.C.) were made for quality assurance to check farmer-recorded data and to ensure there were no problems with data recording. Any persistent issues with data collection or inconsistency in cattle locations that could not be retrospectively validated or corrected, resulted in data from seven farms being excluded from analysis.

Throughout the study it was found that some cattle were grazed in multiple fields at a time (gates between adjacent fields being left open). To allow for this in the analysis such fields were combined and treated as one grazing unit with the total summed area used to calculate stocking densities.

\section{Bovine tuberculosis}

The Department of Agriculture, Environment and Rural Affairs (DAERA), Northern Ireland provided the frequency of bovine tuberculosis herd breakdowns on each study farm for the one, three and five year periods prior to this study. A data sharing agreement was signed between parties with landowner data anonymised such that shared data complied with the Data Protection Act (1998) and General Data Protection Regulation (GDPR) 2016/679. The recent 
historical status of bTB rather than the future status of the farm was analysed due to the badger

Test Vaccinate or Remove study being performed in the area by DAERA which may have influenced future herd bTB tests. Doyle et al. (2016) found farms with historic bTB breakdowns were statistically more likely to have a future breakdown, therefore we argue that using historic bTB status is a reasonable proxy for future risk. It is reasonable to assume that herd management at grass stayed relatively consistent year on year, as none of the study farms advised of new grazing practices.

\section{Statistical analyses}

Descriptive statistics (medians, 95\% confidence intervals (CI), ranges, Mann-Whitney, Kruskal-Wallis and Fishers Exact tests) were used to summarise patterns in stocking densities, percentage of days spent on fragmented land (land not contiguous to the main land parcel), number of moves, and the distances between consecutive pastures between cattle batch life stages and production systems. The distance of all farm movements was collected for each individual move (field to field, field to housing and vice versa) and then totalled for each farm to give the total distance of farm movements. The centroid of each field was used to calculate the distance of movements. Variation in bovine tuberculosis outbreak history per herd $(0 / 1)$ was analysed using Generalised Linear Models (GLM) assuming a binomial error structure and a logit link function. Bovine tuberculosis history (one, three and five year) was modelled as the outcome variable and stocking density, area grazed, total number of cattle movements, distance of movements, days spent on fragmented land and length of grazing season modelled separately as explanatory variables. Analyses were conducted using R v3.4.2 (R Core Team, 2018) with the packages rcompanion (Mangiafico, 2019) and ggplot2 (Wickham, 2016). The package adehabitatHR (Calenge, 2006) was also used to calculate the extent (hectare) of the $95 \%$ and 100\% Minimum Convex Polygons (MCP) of fields grazed. Farm movement data was 
calculated at the farm-level only to account for cattle batches maturing and entering the next stage in production during the grazing season.

\section{Results}

A total of $18 / 25(72 \%)$ of farms collected data that met our quality assurance validation and were retained for analysis. Usable data were collected from the $2^{\text {nd }}$ May to the $30^{\text {th }}$ November 2016 (213 consecutive grazing days) at 7 dairy farms (39\%) and 11 beef farms (61\%). A summary of the dairy and beef farm attributes is shown in Table 1.

Median stocking density was 4.7 animals/ha (95\%CI $4.7-4.8$, range $0.5-143.8)$. Median stocking densities in dairy production (6.6 animals/ha, 95\%CI $6.5-6.7$, range $0.9-143.8$ ) were significantly higher than beef production ( 4.1 animals/ha, 95\%CI $4.1-4.1$, range 0.5 45.3; Mann-Whitney $\mathrm{W}=33221000, p<0.001)$ and varied significantly between batch life history stages (Kruskal-Wallis $\chi_{\mathrm{df}=3}^{2}=1990.1, p<0.001$ ) being highest for dairy cows and lowest for beef bullocks (Fig. 1a). Bovine tuberculosis history during one, three and five years prior to the study was unrelated to stocking density $\left(\mathrm{GLM} \chi_{\mathrm{df}=1}^{2}=0.11 p=0.76 ; \chi_{\mathrm{df}=1}^{2}=0.18, p=0.67\right.$; and $\chi_{\mathrm{df}=1}^{2}=1.25, p=0.30$ respectively).

Median number of land parcels per farm was $3.5(95 \% \mathrm{CI} 2$ - 4, range 1 - 8) with dairy herds utilising on average 4 land parcels (95\%CI $2-4$, range 2 - 6) and beef herds 3 land parcels $(95 \%$ CI $2-5$, range $1-8)$. Cattle movements occurred within an area covering $54 \mathrm{~km}^{2}$ $\left(100 \% \mathrm{MCP}\right.$ of all fields) with the majority within $28 \mathrm{~km}^{2}(95 \% \mathrm{MCP})$. The extent of the area covered by grazing on each farm did not differ between production systems (100\% MCP MannWhitney $\mathrm{W}=28, p=0.38,95 \%$ MCP Mann-Whitney $\mathrm{W}=23, p=0.18$, Fig. 2). Bovine tuberculosis history during one, three and five years prior to the study was unrelated to the extent of the area grazed regardless if it was the $100 \% \mathrm{MCP}\left(\mathrm{GLM} \chi_{\mathrm{df}=1}^{2}=0.96 p=0.33\right.$; $\chi_{\mathrm{df}=1}^{2}=0.48, p=0.49$; and $\chi_{\mathrm{df}=1}^{2}=0.15, p=0.70$ respectively) or $95 \% \mathrm{MCP}$ that was examined $\left(\mathrm{GLM} \chi_{\mathrm{df}=1}^{2}=2.31, p=0.15 ; \chi_{\mathrm{df}=1}^{2}=1.96, p=0.18\right.$; and $\chi_{\mathrm{df}=1}^{2}=1.86, p=0.20$ respectively). 
All farms (100\%) moved batches of cattle between fields throughout the grazing season with a total of 991 separate movement events across the 18 farms (median $=44$ cattle movements per farm per season, range 10 - 149 movements per farm). Number of moves per farm was significantly higher for dairy than beef production systems (Mann-Whitney $\mathrm{W}=2, p=0.001$; Table 1). Bovine tuberculosis history during one, three and five years prior to the study was unrelated to number of cattle moves per farm $\left(\mathrm{GLM} \chi_{\mathrm{df}=1}^{2}=3.22 p=0.11 ; \chi_{\mathrm{df}=1}^{2}=2.83, p=0.12\right.$; and $\chi_{\mathrm{df}=1}^{2}=4.58, p=0.07$ respectively).

The median total distance of farm movements between consecutively occupied fields was $27.5 \mathrm{~km}$ (range $2.4-107.6 \mathrm{~km}$ ) with a total distance of $592.3 \mathrm{~km}$ across all 18 study farms throughout the grazing season. There was no difference in the total distance of farm moves between production systems (Mann-Whitney $\mathrm{W}=20, p=0.10$ ). The median distance of individual moves for dairy, beef and all farms were $242 \mathrm{~m}, 244 \mathrm{~m}$ and $242 \mathrm{~m}$ respectively. There was no difference in the individual length of moves between beef and dairy herds (MannWhitney $\mathrm{W}=110030, \mathrm{p}$-value $=0.38$ ). Bovine tuberculosis history during one, three and five years prior to the study was unrelated to the distances cattle were moved on each farm (GLM $\chi_{\mathrm{df}=1}^{2}=3.62 p=0.09 ; \chi_{\mathrm{df}=1}^{2}=6.52, p=0.05 ;$ and $\chi_{\mathrm{df}=1}^{2}=3.76, p=0.11$ respectively).

A total of 16/18 farms (89\%) had fragmented land disjunct from the main/home farm and just 2/18 (11\%) had all their fields within the main/home farm (both beef production systems). A total of 14/18 farms (78\%) grazed cattle on fragmented land with $4 / 18$ herds $(22 \%)$ grazing at the main/home farm only ( 3 beef and 1 dairy production systems). Two beef herds (11\%) did not graze cattle at the main/home farm during the entire grazing season. 6 of the 7 dairy farms (86\%) grazed cattle on fragmented land though dairy cows (lactating and dry) spent all their time on the main/home farm (0 days on fragmented land). 
Median percentage of time herds spent on fragmented land was $38 \%$ of days (95\% CIs 15.6 -

222

223

224 $55.6 \%$, range $=0-100 \%$ ). The total time spent on fragmented land differed significantly between production systems $\left(\chi_{\mathrm{df}=1}^{2}=72.913, p<0.001\right.$, Table $\left.2 \mathrm{~b}\right)$ and between batch life history stages $\left(\chi_{\mathrm{df}=3}^{2}=4098.3, p<0.001\right)$ with dairy cows and heifers spending the greatest time on the main/home farm and beef bullocks most on fragmented land parcels (Table $2 \mathrm{~b}$ ). The median percentage of days batches of cattle on farms spent on fragmented land is shown in Fig. 1b.

Bovine tuberculosis history one, three and five years prior to the study was unrelated to time spent on fragmented land $\left(\operatorname{GLM} \chi_{\mathrm{df}=1}^{2}=0.71 p=0.43 ; \chi_{\mathrm{df}=1}^{2}=4.24, p=0.08\right.$; and $\chi_{\mathrm{df}=1}^{2}=3.09$, $p=0.12$ respectively).

There was a total of 18,988 grazing days with cattle spending 11,627 days in single field compartments and 7,361 days in combined/multiple field compartments. Time spent in combined/multiple field compartments varied significantly between dairy and beef herds $\left(\chi^{2} \mathrm{df}=1\right.$ $=39.865, p<0.001)$ and batch life stages $\left(\chi_{\mathrm{df}=3}^{2}=1398.2, \mathrm{p}<0.001\right)$ with calves, cows and heifers (i.e. dairy animals) spending most time in single field compartments (Table 2a).

There was no difference in the grazing season duration between dairy and beef production systems (Mann-Whitney $\mathrm{W}=32, p=0.58$; Table 1 ). Bovine tuberculosis history during one, three and five years prior to the study was unrelated to grazing season duration (GLM $\chi_{\mathrm{df}=1}^{2}=1.14, p=0.34 ; \chi_{\mathrm{df}=1}^{2}=1.32, p=0.28 ;$ and $\chi_{\mathrm{df}=1}^{2}=0.51, p=0.48$ respectively).

\section{Discussion}

There is a paucity of basic data quantifying simple farm management practices such as the frequency of intraherd cattle movements, use of consolidated or spatially fragmented pastures and duration of time at grass. Here, we provide a case study example of cattle movement metrics for a sample of eighteen farms in Northern Ireland highlighting the high frequency of 
cattle movements and use of fragmented land which hitherto has not been accounted for in analyses of bovine tuberculosis epidemiology. The results from this study highlight the variability in stocking densities and movement metrics even within a small study population. These results would likely vary across landscapes and farming cultures and may not be directly comparable to other geographical locations but should highlight the need to understand local grazing management when trying to model bTB dynamics across time and space. If tailored biosecurity advice is developed on a per herd basis, an understanding of the intra-inter- herd exposure/risk would be beneficial.

Dairy production systems had the largest herd size and highest stocking density whilst the higher metabolic demands of milk production compared to other life history stages (MSD Ltd, 2017) necessitated twice the number of moves than beef production systems. In dairy systems, available grass was likely to be exhausted sooner than for lower density, less energetically demanding life stages. Dairy cows were stocked at highest densities and are known to be at with dairy cows spending zero days on fragmented land, potentially reducing their exposure to neighbouring herds. Whilst this may be expected for lactating cows, even dry cows were retained on home fields on the seven dairy farms likely due to dry cows being near their calving on non-fragmented land only, may potentially reduce the number of neighbouring herds exposed.

All life stages of beef cattle are typically grazed at lower stocking densities than dairy cattle. Some groups of cattle were given access to multiple fields at the same time, this occurred more frequently with batches of beef cattle than with dairy cows, which were grazed in single fields 
more commonly. Allowing beef cattle access to multiple fields simultaneously may explain their lower stocking densities. By maintaining lower density, more spatially dispersed stocking; may potentially reduce intraherd contact rates (re: disease transmission) and density-dependent physiological stresses that may make animals more vulnerable to infection.

Beef farms had the longest distances moved per farm, whilst beef bullocks spent the most time on fragmented land (though median individual distances moved were similar between beef and dairy systems). These animals may therefore be at greatest risk of disease transmission but are ultimately removed from the herd after being taken for slaughter.

We found substantial variation in the extent of grazed land (MCPs of grazed fields). Some farms in the current study had up to 8 spatially disjunct land parcels resulting in greater numbers of boundaries with adjacent farms (likely increasing the time cattle spend adjacent to other herds increasing across-the-hedge (nose-to-nose) contact). Thus, a bTB free herd in greater contact with adjacent herds may be at a higher infection risk than those herds that spend their time on consolidated single land parcels and a bTB infected herd occupying or being moved between numerous disjunct land parcels may come into contact with adjacent bTB free herds exposing them to potential infection. Herds that cover larger areas may come into contact with an increased number of badger social groups, due to the differences in bTB prevalence within different badger social groups (Delahay et al., 2000), the risk of M. bovis transmission may be increased.

None of the farm or herd attributes in terms of stocking densities, frequency of movements, distance of movements and fragmentation of grazing land influenced a herd's bTB outbreak status, regardless of the window examined (1,3 or 5 years prior to study). There was a weak positive trend for bovine tuberculosis outbreaks during the 3 years prior to study with distances cattle were moved $(p=0.05)$ and time spent on fragmented land $(p=0.08)$. This could be due to 
random chance (at $\alpha=0.95$ about $1 / 20$ tests are likely to be significant by random chance) but it may also be that the small sample size (18 farms) provided low statistical power to quantify

297 relationships; thus greater numbers of observations may resolve these relationships. Nevertheless, Brown et al. (2019) suggested that herd connectivity may play an important role in the bTB maintenance in Northern Ireland, mirroring findings from elsewhere (Gilbert et al., 2005; Palisson et al., 2016). The Department of Agriculture, Environment and Rural Affairs (DAERA) restrict herd movements after bTB breakdown to prevent exposing other herds, for example, at cattle sales, markets and shows but there are currently no restrictions on intraherd movement (despite considerable frequency of movement including to fragmented land for some herds). Such restrictions would be logistically hard to enforce but herd owners with a bTB breakdown should be recommended to evaluate and try to minimise intraherd movements to reduce transmission risk to a new herd. Where practical, these approaches may allow a reduction in the spatial exposure to neighbours, and indirectly to wildlife hosts (Campbell et al., 2019).

\section{Acknowledgements}

The authors would like to thank the farmers in the study area for meticulously recording their cattle movements across the grazing season. Also, to acknowledge the staff in AFBI and DAERA who surveyed and recorded the locations of badger setts and latrines during the TVR project.

\section{Funding}

This research was funded as part of a PhD studentship by the Department of Agriculture, Environment and Rural Affairs, Northern Ireland. 


\section{References}

Aalen, F.H.A., 1963. A review of recent Irish population trends. Popul. Stud. (NY). 17, 73-78. https://doi.org/10.1080/00324728.1963.10405754

Allen, A.R., Skuce, R.A., Byrne, A.W., 2018. Bovine Tuberculosis in Britain and Ireland - A Perfect Storm? the Confluence of Potential Ecological and Epidemiological Impediments to Controlling a Chronic Infectious Disease. Front. Vet. Sci. 5, 109. https://doi.org/10.3389/fvets.2018.00109

Brennan, M.L., Kemp, R., Christley, R.M., 2008. Direct and indirect contacts between cattle farms in north-west England. Prev. Vet. Med. 84, 242-260. https://doi.org/https://doi.org/10.1016/j.prevetmed.2007.12.009

Broughan, J.M., Judge, J., Ely, E., Delahay, R.J., Wilson, G., Clifton-Hadley, R.S., Goodchild, A. V., Bishop, H., Parry, J.E., Downs, S.H., 2016. A review of risk factors for bovine tuberculosis infection in cattle in the UK and Ireland. Epidemiol. Infect. 144, 2899-2926. https://doi.org/10.1017/S095026881600131X

Brown, E., Marshall, A.H., Mitchell, H.J., Byrne, A.W., 2019. Cattle movements in Northern Ireland form a robust network: implications for disease management. Prev. Vet. Med. 170, 104740. https://doi.org/10.1016/j.prevetmed.2019.104740

Byrne, A.W., Graham, J., Brown, C., Donaghy, A., Guelbenzu-Gonzalo, M., McNair, J., Skuce, R., Allen, A., McDowell, S., 2017. Bovine tuberculosis visible lesions in cattle culled during herd breakdowns: the effects of individual characteristics, trade movement and co-infection. BMC Vet. Res. 13, 400. https://doi.org/10.1186/s12917-017-1321-z

Byrne, A.W.W., Kenny, K., Fogarty, U., O’Keeffe, J.J., More, S.J.J., McGrath, G., Teeling, M., Martin, S.W.W., Dohoo, I.R.R., O’Keeffe, J.J., More, S.J.J., McGrath, G., Teeling, M., Martin, S.W.W., Dohoo, I.R.R., 2015. Spatial and temporal analyses of metrics of tuberculosis infection in badgers (Meles meles) from the Republic of Ireland: Trends in apparent prevalence. Prev. Vet. Med. 122, 345-354. https://doi.org/10.1016/j.prevetmed.2015.10.013

Campbell, E.L., Byrne, A.W., Menzies, F.D., McBride, K.R., McCormick, C.M., Scantlebury, M., Reid, N., 2019. Interspecific visitation of cattle and badgers to fomites: A transmission risk for bovine tuberculosis? Ecol. Evol. 9, 8479-8489. https://doi.org/10.1002/ece3.5282

Collins, J.D., 2006. Tuberculosis in cattle: Strategic planning for the future. Vet. Microbiol. 112, 369381. https://doi.org/10.1016/J.VETMIC.2005.11.041

DAERA, 2018. Bovine Tuberculosis in Northern Ireland 2017 Annual Report. Belfast, Northern Ireland.

Delahay, R.J., Langton, S., Smith, G.C., Clifton-Hadley, R.S., Cheeseman, C.L., 2000. The spatiotemporal distribution of Mycobacterium bovis (bovine tuberculosis) infection in a high-density badger population. J. Anim. Ecol. 69, 428-441. https://doi.org/10.1046/j.13652656.2000.00406.x

Dommergues, L., Rautureau, S., Petit, E., Dufour, B., 2012. Network of Contacts between Cattle Herds in a French Area Affected by Bovine Tuberculosis in 2010. Transbound. Emerg. Dis. 59, 292-302. https://doi.org/10.1111/j.1865-1682.2011.01269.x

Doyle, L.P., Courcier, E.A., Gordon, A.W., O’Hagan, M.J.H., Menzies, F.D., 2016. Bovine tuberculosis in Northern Ireland: Risk factors associated with duration and recurrence of chronic herd breakdowns. Prev. Vet. Med. 131, 1-7. https://doi.org/10.1016/j.prevetmed.2016.06.016

Doyle, L.P., Gordon, A.W., Abernethy, D.A., Stevens, K., 2014. Bovine tuberculosis in Northern Ireland: Risk factors associated with time from post-outbreak test to subsequent herd breakdown. Prev. Vet. Med. 116, 47-55. https://doi.org/10.1016/j.prevetmed.2014.06.010 
Durr, P.A., Froggatt, A.E.A., 2002. How best to geo-reference farms? A case study from Cornwall, England. Prev. Vet. Med. 56, 51-62. https://doi.org/10.1016/S0167-5877(02)00123-X

Gates, M.C., Humphry, R.W., Gunn, G.J., Woolhouse, M.E.J., 2014. Not all cows are epidemiologically equal: Quantifying the risks of bovine viral diarrhoea virus (BVDV) transmission through cattle movements. Vet. Res. 45, 110. https://doi.org/10.1186/s13567-014$0110-\mathrm{y}$

Gilbert, M., Mitchell, A., Bourn, D., Mawdsley, J., Clifton-Hadley, R., Wint, W., 2005. Cattle movements and bovine tuberculosis in Great Britain. Nature 435, 491-496. https://doi.org/10.1038/nature03548

Griffin, J.M., Hahesy, T., Lynch, K., Salman, M.D., McCarthy, J., Hurley, T., 1993. The association of cattle husbandry practices, environmental factors and farmer characteristics with the occurence of chronic bovine tuberculosis in dairy herds in the Republic of Ireland. Prev. Vet. Med. 17, 145-160. https://doi.org/10.1016/0167-5877(93)90025-O

Herzog, A., Winckler, C., Zollitsch, W., 2018. In pursuit of sustainability in dairy farming: A review of interdependent effects of animal welfare improvement and environmental impact mitigation. Agric. Ecosyst. Environ. 267, 174-187. https://doi.org/10.1016/j.agee.2018.07.029

Milne, G.M., Graham, J., Allen, A., Lahuerta-Marin, A., McCormick, C., Presho, E., Skuce, R., Byrne, A.W., 2019a. Spatiotemporal analysis of prolonged and recurrent bovine tuberculosis breakdowns in Northern Irish cattle herds reveals a new infection hotspot. Spat. Spatiotemporal. Epidemiol. 28, 33-42. https://doi.org/10.1016/j.sste.2018.11.002

Milne, G.M., Graham, J., Allen, A., McCormick, C., Presho, E., Skuce, R., Byrne, A.W., $2019 \mathrm{~b}$. Variation in Mycobacterium bovis genetic richness suggests that inwards cattle movements are a more important source of infection in beef herds than in dairy herds. BMC Microbiol. 19, 154. https://doi.org/10.1186/s12866-019-1530-7

MSD Ltd, 2017. Nutritional Requirements of Dairy Cattle - Management and Nutrition - Veterinary Manual. MSD Vet. Man. URL https://www.msdvetmanual.com/management-andnutrition/nutrition-dairy-cattle/nutritional-requirements-of-dairy-cattle (accessed 1.5.20).

Neill, S.D., Hanna, J., O’Brien, J.J., McCracken, R.M., 1989. Transmission of tuberculosis from experimentally infected cattle to in-contact calves. Vet. Rec. 124, 269-271. https://doi.org/10.1136/vr.124.11.269

O'Reilly, L.M., Daborn, C.J., 1995. The epidemiology of Mycobacterium bovis infections in animals and man: A review. Tuber. Lung Dis. 76, 1-46. https://doi.org/10.1016/0962-8479(95)90591-X

Palisson, A., Courcoul, A., Durand, B., 2016. Role of cattle movements in bovine Tuberculosis spread in France between 2005 and 2014. PLoS One 11. https://doi.org/10.1371/journal.pone.0152578

Phillips, C.J.., Foster, C.R.., Morris, P.., Teverson, R., 2003. The transmission of Mycobacterium bovis infection to cattle. Res. Vet. Sci. 74, 1-15. https://doi.org/10.1016/S0034-5288(02)001455

Ramírez-Villaescusa, A.M., Medley, G.F., Mason, S., Green, L.E., 2009. Herd and individual animal risks associated with bovine tuberculosis skin test positivity in cattle in herds in south west England. Prev. Vet. Med. 92, 188-198. https://doi.org/10.1016/j.prevetmed.2009.08.011

Robinson, S.E., Christley, R.M., 2007. Exploring the role of auction markets in cattle movements within Great Britain. Prev. Vet. Med. 81, 21-37. https://doi.org/10.1016/j.prevetmed.2007.04.011

Vial, F., Johnston, W.T., Donnelly, C.A., 2011. Local cattle and badger populations affect the risk of confirmed tuberculosis in British cattle herds. PLoS One 6, e18058. https://doi.org/10.1371/journal.pone.0018058 
White, P.W., Martin, S.W., De Jong, M.C.M., O’Keeffe, J.J., More, S.J., Frankena, K., 2013. The importance of "neighbourhood" in the persistence of bovine tuberculosis in Irish cattle herds. Prev. Vet. Med. 110, 346-355. https://doi.org/10.1016/j.prevetmed.2013.02.012

Wright, D.M., Reid, N., Ian Montgomery, W., Allen, A.R., Skuce, R.A., Kao, R.R., 2015. Herd-level bovine tuberculosis risk factors: assessing the role of low-level badger population disturbance. Sci. Rep. 5, 13062. https://doi.org/10.1038/srep13062 


\begin{tabular}{|c|c|c|c|c|}
\hline Attribute & Beef $(n=11)$ & Dairy $(n=7)$ & Both $(n=18)$ & $\begin{array}{c}\text { P-value Dairy Vs. Beef } \\
\text { (Test) }\end{array}$ \\
\hline Farm size (hectares) & $\begin{array}{c}39 \\
(95 \% \text { CI } 23-55, \text { range } 11- \\
112)\end{array}$ & $\begin{array}{c}64 \\
(95 \% \text { CI 60-119, range 20- } \\
140)\end{array}$ & $\begin{array}{c}50 \\
(95 \% \text { CI } 33-70, \text { range } 11- \\
140)\end{array}$ & 0.06 (Mann-Whitney) \\
\hline Fields/farm (number) & $\begin{array}{c}31 \\
(95 \% \text { CI } 17-38, \text { range } 8-84)\end{array}$ & $\begin{array}{c}40 \\
(95 \% \text { CI 29-63, range } 25- \\
101)\end{array}$ & $\begin{array}{c}34 \\
(95 \% \text { CI } 25-43, \text { range } 8- \\
101)\end{array}$ & 0.14 (Mann-Whitney) \\
\hline Herd size (cattle) & $\begin{array}{c}43 \text { cattle } \\
(95 \% \text { CI } 30-80, \text { range } 11- \\
114)\end{array}$ & $\begin{array}{c}168 \text { cattle } \\
(95 \% \text { CI } 123-240, \text { range } 65- \\
266)\end{array}$ & $\begin{array}{c}74 \text { cattle } \\
\text { (95\%CI 36-151, range } 11- \\
266) \\
\end{array}$ & $<0.001$ (Mann-Whitney) \\
\hline $\begin{array}{l}\text { Grazing season duration } \\
\text { (days) }\end{array}$ & $\begin{array}{c}204 \text { days } \\
(95 \% \text { CI } 183->213, \text { range } \\
180->213)\end{array}$ & $\begin{array}{c}209 \text { days } \\
(95 \% \text { CI } 186->213, \text { range } \\
180->213)\end{array}$ & $\begin{array}{c}205 \text { days } \\
(95 \% \text { CI } 190->213, \text { range } \\
180->213)\end{array}$ & 0.58 (Mann-Whitney) \\
\hline Median Stocking Density & $\begin{array}{c}4.1 \text { animals } / \text { ha } \\
(95 \% \text { CI } 4.1-4.1 \text {, range } 0.5- \\
45.3) \\
\end{array}$ & $\begin{array}{c}6.6 \text { animals } / \text { ha } \\
(95 \% \text { CI } 6.5-6.7, \text { range } 0.9- \\
143.8) \\
\end{array}$ & $\begin{array}{c}4.7 \text { animals/ha } \\
(95 \% \text { CI } 4.7-4.8, \text { range } 0.5- \\
143.8) \\
\end{array}$ & $<0.001$ (Mann-Whitney) \\
\hline Total number of fields & 360 & 337 & 697 & \\
\hline $\begin{array}{l}\text { bTB outbreak in previous } \\
\text { year } \\
\text { (\% of herds })\end{array}$ & $\begin{array}{c}9 \\
(1 / 11)\end{array}$ & $\begin{array}{c}29 \\
(2 / 7)\end{array}$ & $\begin{array}{c}17 \\
(3 / 18)\end{array}$ & 0.53 (Fishers Exact Test) \\
\hline $\begin{array}{l}\text { bTB outbreak in previous } \\
3 \text { years } \\
(\% \text { of herds })\end{array}$ & $\begin{array}{c}36 \\
(4-/ 1)\end{array}$ & $\begin{array}{c}57 \\
(4 / 7)\end{array}$ & $\begin{array}{c}44 \\
(8 / 18)\end{array}$ & 0.63 (Fishers Exact Test) \\
\hline $\begin{array}{l}\text { bTB outbreak in previous } \\
5 \text { years } \\
(\% \text { of herds })\end{array}$ & $\begin{array}{c}46 \\
(5 / 11)\end{array}$ & $\begin{array}{c}86 \\
(6 / 7)\end{array}$ & $\begin{array}{c}61 \\
(11 / 18)\end{array}$ & 0.15 (Fishers Exact Test) \\
\hline $\begin{array}{l}\text { Total number of } \\
\text { movements }\end{array}$ & 318 & 673 & 991 & \\
\hline Number of moves/farm & $\begin{array}{c}22 \\
(95 \% \text { CI } 13-42, \text { range } 10- \\
76)\end{array}$ & $\begin{array}{c}89 \\
(95 \% \text { CI } 70-118, \text { range } 68- \\
149) \\
\end{array}$ & $\begin{array}{c}44 \\
(95 \% \text { CI } 21-83 \text {, range } 10- \\
149) \\
\end{array}$ & $<0.001$ (Mann-Whitney) \\
\hline $\begin{array}{l}\text { Total distance of all moves } \\
(\mathrm{km})\end{array}$ & 277 & 315 & 592 & \\
\hline $\begin{array}{l}\text { Distance of moves/farm } \\
(\mathrm{km})\end{array}$ & $\begin{array}{c}12 \\
(95 \% \text { CI } 6-46, \text { range } 2-78)\end{array}$ & $\begin{array}{c}38 \\
(95 \% \text { CI } 36-41, \text { range } 17- \\
108) \\
\end{array}$ & $\begin{array}{c}28 \\
\text { (95\%CI } 11-41, \text { range 2- } \\
108) \\
\end{array}$ & 0.10 (Mann-Whitney) \\
\hline $\begin{array}{l}\text { Distance of individual } \\
\text { moves }(\mathrm{m})\end{array}$ & $\begin{array}{c}244 \\
(95 \% \text { CI 226-268, range 70- } \\
6,339) \\
\end{array}$ & $\begin{array}{c}242 \\
(95 \% \text { CI } 225-262, \text { range } 4- \\
3-, 579)\end{array}$ & $\begin{array}{c}242 \\
(95 \% \text { CI } 229-262, \text { range } 43- \\
6,339)\end{array}$ & 0.38 (Mann-Whitney) \\
\hline $\begin{array}{l}100 \% \text { MCP for movement } \\
\text { extent (ha) }\end{array}$ & $\begin{array}{c}67.3 \\
(95 \% \text { CI 16-314, range 5- } \\
542)\end{array}$ & $\begin{array}{c}151 \\
(95 \% \mathrm{CI} 41-306, \text { range } 40- \\
364)\end{array}$ & $\begin{array}{c}99.4 \\
(95 \% \text { CI 34-228, range 5- } \\
542)\end{array}$ & 0.38 (Mann-Whitney) \\
\hline $\begin{array}{l}95 \% \text { MCP for movement } \\
\text { extent (ha) }\end{array}$ & $\begin{array}{c}24 \\
(95 \% \text { CI } 12-138, \text { range } 2- \\
381)\end{array}$ & $\begin{array}{c}123 \\
(95 \% \mathrm{CI} 43-305, \text { range } 35- \\
332)\end{array}$ & $\begin{array}{c}95.4 \\
(95 \% \text { CI } 24-156, \text { range } 2- \\
381)\end{array}$ & 0.18 (Mann-Whitney) \\
\hline
\end{tabular}

$449 \quad$ Table 1 Descriptive statistics (totals, medians, ranges and confidence intervals (CI)) summarising farm, cattle 450 herd and movement attributes of beef and dairy production systems for $n=18$ in County Down, Northern Ireland 451 during the grazing season $\left(2^{\text {nd }}\right.$ May $-30^{\text {th }}$ November 2016). Units for each metrics are stated in brackets. 


\begin{tabular}{|c|c|c|c|c|c|c|}
\hline \multirow{2}{*}{$\begin{array}{l}\text { Life stage / Production } \\
\text { i) Batch }\end{array}$} & \multicolumn{3}{|c|}{ a) Field arrangement } & \multicolumn{3}{|c|}{ Test of association } \\
\hline & Single & Multiple & Total & $\chi^{2}$ & df & $p$ \\
\hline Bullocks & $3,725(48 \%)$ & $4,098(52 \%)$ & $7,823(41 \%)$ & 1398.2 & 3 & $<0.001$ \\
\hline Calves & $1,656(73 \%)$ & $605(27 \%)$ & $2,261(12 \%)$ & & & \\
\hline Cows & $3,378(80 \%)$ & $824(20 \%)$ & $4,202(22 \%)$ & & & \\
\hline Heifers & $2,868(61 \%)$ & $1,834(39 \%)$ & $4,702(25 \%)$ & & & \\
\hline Sub-total & $11,627(100 \%$ & 7,361 (100\%) & $18,988(100 \%$ & & & \\
\hline \multicolumn{7}{|l|}{ ii) Production } \\
\hline Beef & $5,677(59 \%)$ & $3,941(41 \%)$ & $9,618(51 \%)$ & 39.9 & 1 & $<0.001$ \\
\hline Dairy & $5,950(63 \%)$ & $3,420(37 \%)$ & $9,370(49 \%)$ & & & \\
\hline \multirow[t]{2}{*}{ Sub-total } & $11,627(100 \%)$ & 7,361 (100\%) & $18,988(100 \%)$ & & & \\
\hline & \multicolumn{3}{|c|}{ b) Field contiguity } & & & \\
\hline i) Batch & Main/home & Fragmented & Total & & & \\
\hline Bullocks & $2,570(33 \%)$ & $5,253(67 \%)$ & $7,823(41 \%)$ & 4098.3 & 3 & $<0.001$ \\
\hline Calves & $1,353(60 \%)$ & $908(40 \%)$ & $2,261(12 \%)$ & & & \\
\hline Cows & 3,922 (93\%) & $280(7 \%)$ & $4,202(22 \%)$ & & & \\
\hline Heifers & $2,746(58 \%)$ & $1,956(42 \%)$ & $4,702(25 \%)$ & & & \\
\hline Sub-total & 10,591 (100\%) & $8,397(100 \%)$ & $18,988(100 \%)$ & & & \\
\hline \multicolumn{7}{|l|}{ ii) Production } \\
\hline Beef & $5,072(53 \%)$ & $4546(47 \%)$ & $9618(51 \%)$ & 72.9 & 1 & $<0.001$ \\
\hline Dairy & $5,519(59 \%)$ & $3851(41 \%)$ & $9370(49 \%)$ & & & \\
\hline Sub-total & 10,591 (100\%) & 8,397 (100\%) & 18,988 (100\%) & & & \\
\hline
\end{tabular}

463 Table 2 Frequency (total number of days) of cattle use of a) field arrangements (single verses multiple fields per patch) and b) field contiguity (home verses fragmented) for $n=18$ farms.

465

466

467

468

469

470

471

472

473

474

475

476 

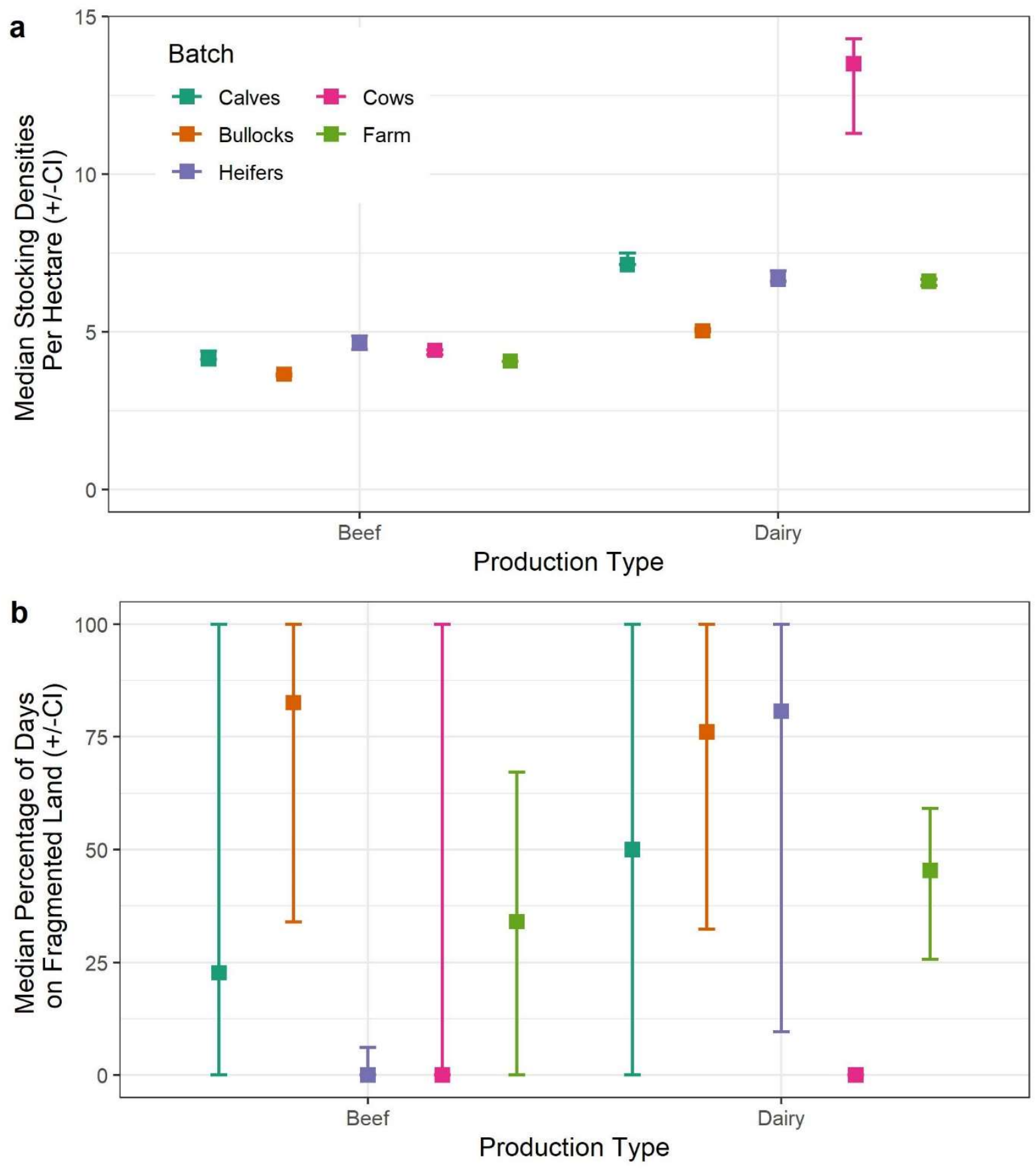

Fig. 1 Median $\pm 95 \%$ confidence intervals (CI) for a) stocking densities for each cattle life history stage season 
a) All 18 farms

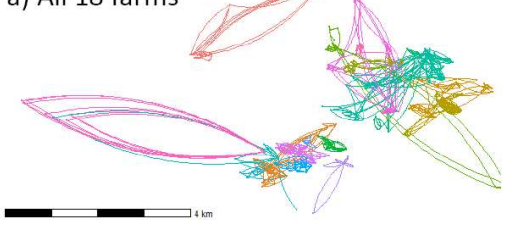

b) 11 beef farms

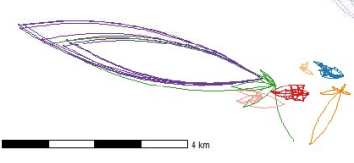

c) 7 dairy farms
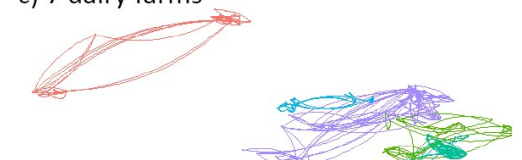

482

483

484

485

486

487
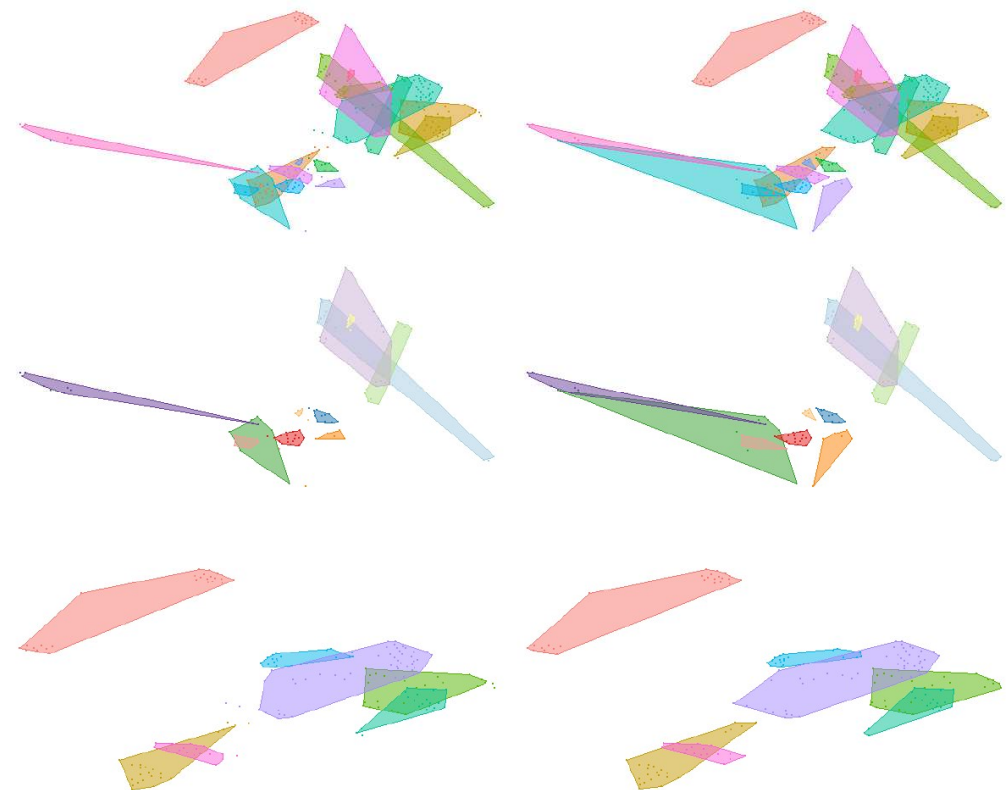

Fig 2 Networked cattle movements (lines) between centroid of fields (dots) for a) $n=18$ all farms, b) $n=11$ beef farms and c) $n=7$ dairy farms (left column) and corresponding Minimum Convex Polygons (both 95\% and 100\%) for fields within the same categories. Each colour represents an individual herd. 
STROBE 2007 (v4) checklist of items to be included in reports of observational studies in epidemiology* Checklist for cohort, case-control, and cross-sectional studies (combined)

\begin{tabular}{|c|c|c|c|}
\hline Section/Topic & Item \# & Recommendation & Reported on page \# \\
\hline \multirow[t]{2}{*}{ Title and abstract } & \multirow[t]{2}{*}{1} & (a) Indicate the study's design with a commonly used term in the title or the abstract & 3 \\
\hline & & (b) Provide in the abstract an informative and balanced summary of what was done and what was found & 3 \\
\hline \multicolumn{4}{|l|}{ Introduction } \\
\hline Background/rationale & 2 & Explain the scientific background and rationale for the investigation being reported & $4-6$ \\
\hline Objectives & 3 & State specific objectives, including any pre-specified hypotheses & 6 \\
\hline \multicolumn{4}{|l|}{ Methods } \\
\hline Study design & 4 & Present key elements of study design early in the paper & 6 \\
\hline Setting & 5 & $\begin{array}{l}\text { Describe the setting, locations, and relevant dates, including periods of recruitment, exposure, follow-up, and data } \\
\text { collection }\end{array}$ & $6-7$ \\
\hline \multirow[t]{2}{*}{ Participants } & \multirow[t]{2}{*}{6} & $\begin{array}{l}\text { (a) Cohort study-Give the eligibility criteria, and the sources and methods of selection of participants. Describe } \\
\text { methods of follow-up } \\
\text { Case-control study-Give the eligibility criteria, and the sources and methods of case ascertainment and control } \\
\text { selection. Give the rationale for the choice of cases and controls } \\
\text { Cross-sectional study-Give the eligibility criteria, and the sources and methods of selection of participants }\end{array}$ & $6-7$ \\
\hline & & $\begin{array}{l}\text { (b) Cohort study-For matched studies, give matching criteria and number of exposed and unexposed } \\
\text { Case-control study-For matched studies, give matching criteria and the number of controls per case }\end{array}$ & \\
\hline Variables & 7 & $\begin{array}{l}\text { Clearly define all outcomes, exposures, predictors, potential confounders, and effect modifiers. Give diagnostic } \\
\text { criteria, if applicable }\end{array}$ & $7-8$ \\
\hline Data sources/measurement & $8^{*}$ & $\begin{array}{l}\text { For each variable of interest, give sources of data and details of methods of assessment (measurement). Describe } \\
\text { comparability of assessment methods if there is more than one group }\end{array}$ & $6-7$ \\
\hline Bias & 9 & Describe any efforts to address potential sources of bias & 7 \\
\hline
\end{tabular}




\begin{tabular}{|c|c|c|c|}
\hline Study size & 10 & Explain how the study size was arrived at & $6-7$ \\
\hline Quantitative variables & 11 & $\begin{array}{l}\text { Explain how quantitative variables were handled in the analyses. If applicable, describe which groupings were chosen } \\
\text { and why }\end{array}$ & 8 \\
\hline \multirow[t]{5}{*}{ Statistical methods } & \multirow[t]{5}{*}{12} & (a) Describe all statistical methods, including those used to control for confounding & 8 \\
\hline & & (b) Describe any methods used to examine subgroups and interactions & \\
\hline & & (c) Explain how missing data were addressed & \\
\hline & & $\begin{array}{l}\text { (d) Cohort study-If applicable, explain how loss to follow-up was addressed } \\
\text { Case-control study-If applicable, explain how matching of cases and controls was addressed } \\
\text { Cross-sectional study-If applicable, describe analytical methods taking account of sampling strategy }\end{array}$ & 7 \\
\hline & & (e) Describe any sensitivity analyses & \\
\hline \multicolumn{4}{|l|}{ Results } \\
\hline \multirow[t]{3}{*}{ Participants } & $13^{*}$ & $\begin{array}{l}\text { (a) Report numbers of individuals at each stage of study-eg numbers potentially eligible, examined for eligibility, } \\
\text { confirmed eligible, included in the study, completing follow-up, and analysed }\end{array}$ & 8-10, Table 1 \\
\hline & & (b) Give reasons for non-participation at each stage & 8 \\
\hline & & (c) Consider use of a flow diagram & \\
\hline \multirow[t]{3}{*}{ Descriptive data } & $14^{*}$ & $\begin{array}{l}\text { (a) Give characteristics of study participants (eg demographic, clinical, social) and information on exposures and } \\
\text { potential confounders }\end{array}$ & $8-10$ \\
\hline & & (b) Indicate number of participants with missing data for each variable of interest & \\
\hline & & (c) Cohort study-Summarise follow-up time (eg, average and total amount) & 8 \\
\hline \multirow[t]{3}{*}{ Outcome data } & $15^{*}$ & Cohort study-Report numbers of outcome events or summary measures over time & $8-10$ \\
\hline & & Case-control study-Report numbers in each exposure category, or summary measures of exposure & \\
\hline & & Cross-sectional study-Report numbers of outcome events or summary measures & \\
\hline
\end{tabular}




\begin{tabular}{|c|c|c|c|}
\hline Main results & 16 & $\begin{array}{l}\text { (a) Give unadjusted estimates and, if applicable, confounder-adjusted estimates and their precision (eg, 95\% } \\
\text { confidence interval). Make clear which confounders were adjusted for and why they were included }\end{array}$ & 8-10, Table 1 and 2 \\
\hline & & (b) Report category boundaries when continuous variables were categorized & \\
\hline & & (c) If relevant, consider translating estimates of relative risk into absolute risk for a meaningful time period & \\
\hline Other analyses & 17 & Report other analyses done-eg analyses of subgroups and interactions, and sensitivity analyses & \\
\hline \multicolumn{4}{|l|}{ Discussion } \\
\hline Key results & 18 & Summarise key results with reference to study objectives & $8-10$ \\
\hline Limitations & 19 & $\begin{array}{l}\text { Discuss limitations of the study, taking into account sources of potential bias or imprecision. Discuss both direction } \\
\text { and magnitude of any potential bias }\end{array}$ & $8-10$ \\
\hline Interpretation & 20 & $\begin{array}{l}\text { Give a cautious overall interpretation of results considering objectives, limitations, multiplicity of analyses, results } \\
\text { from similar studies, and other relevant evidence }\end{array}$ & 12 \\
\hline Generalisability & 21 & Discuss the generalisability (external validity) of the study results & $12-13$ \\
\hline \multicolumn{4}{|c|}{ Other information } \\
\hline Funding & 22 & $\begin{array}{l}\text { Give the source of funding and the role of the funders for the present study and, if applicable, for the original study on } \\
\text { which the present article is based }\end{array}$ & 13 \\
\hline
\end{tabular}

*Give information separately for cases and controls in case-control studies and, if applicable, for exposed and unexposed groups in cohort and cross-sectional studies. Note: An Explanation and Elaboration article discusses each checklist item and gives methodological background and published examples of transparent reporting. The STROBE checklist is best used in conjunction with this article (freely available on the Web sites of PLoS Medicine at http://www.plosmedicine.org/, Annals of Internal Medicine at http://www.annals.org/, and Epidemiology at http://www.epidem.com/). Information on the STROBE Initiative is available at www.strobe-statement.org. 